\title{
Collective efficacy in soccer teams: a systematic review
}

\author{
Mylena Aparecida Rodrigues Alves ${ }^{*}$ (D, Marcus Vinicius de Souza Lencina, Mayara Juliana Paes and \\ Joice Mara Facco Stefanello
}

\begin{abstract}
Collective efficacy, defined as a group's shared belief about its conjoint capability to organize and execute courses of action, plays a pivotal role in understanding the dynamics of sports teams, since it influences what individuals choose to do as team members, how much they invest in motivational terms to perform actions, how much they work collectively, and for how long they persist despite failure. Through a systematic review, it was investigated how collective efficacy has been assessed in the context of soccer and which indicators, attributes, and psychometric properties have been contemplated in the instruments used. Following the PRISMA guidelines, 22 articles were retrieved through electronic databases (APA PsycINFO; SPORTDiscus; Science Direct; BVS; Web of Science; Scopus; PubMed; and Scielo), using as descriptors, in English, Spanish, and Portuguese, collective efficacy and soccer, combined by the Boolean operators AND and OR. The study did not delimit the initial year of publication for the searches carried out, including all articles found until January 14, 2021 (date of the last update). The following eligibility criteria were adopted: scientific articles published in journals; original studies, which specified the instrument used to assess collective efficacy and carried out with soccer athletes. Five instruments (FCEQ, CEQS, CEI, CEC, and CEQsoccer) that evaluated technical-tactical and psychological attributes associated with collective efficacy in soccer players were identified. In most studies, psychometric properties were restricted to content validity and reliability (internal consistency), and there were no suitable validation processes for the instruments used to measure collective efficacy, which can be considered a limiting factor for understanding this psychological construct in soccer modality.
\end{abstract}

Keywords: Collective efficacy, Group dynamics, Psychometric instrument, Measurement

\section{Introduction}

When we talk about emotions and behaviours in the sports environment, understand the group dynamics and the relationships between group and its members has been highlighted by researchers (Dominski et al., 2018; Fiorese et al., 2019; Trevelin \& Alves, 2019; Vilarino, Andrade, Felden, Fomes, \& Andrade, 2017; Yeemin, Dias, \& Fonseca, 2016) has been highlighted. In collective sports, for example, athletes depend on each other to perform their actions in training and competitions, being this interdependence a valuable condition for the team's success (Feltz, Short, \& Sullivan, 2008; Leo et al., 2019, b).

\footnotetext{
* Correspondence: mylena_cg@hotmail.com
}

Federal University of Paraná (UFPR), Paraná, Brazil
The Social Cognitive Theory explains this phenomenon based on the concept of human agency (Bandura, 2006; Bandura, Azzi, \& Polydoro, 2008). Accordingly, human thinking and behavior are products of the dynamic interrelation between personal, behavioral, and environmental influences. Therefore, the judgment of how capable the team is to perform a task determines the results that this team hopes to achieve from the joint actions (Bandura, 1997).

The shared belief of a group regarding its collective ability to organize and execute courses of action required to produce certain levels of achievement, known as collective efficacy (Bandura, 1997), plays a pivotal role in understanding the dynamics of sports teams (Jowett,
SpringerOpen (c) The Author(s). 2021 Open Access This article is licensed under a Creative Commons Attribution 4.0 International License, which permits use, sharing, adaptation, distribution and reproduction in any medium or format, as long as you give appropriate credit to the original author(s) and the source, provide a link to the Creative Commons licence, and indicate if changes were made. The images or other third party material in this article are included in the article's Creative Commons licence, unless indicated otherwise in a credit line to the material. If material is not included in the article's Creative Commons licence and your intended use is not permitted by statutory regulation or exceeds the permitted use, you will need to obtain permission directly from the copyright holder. To view a copy of this licence, visit http://creativecommons.org/licenses/by/4.0/. 
Shanmugam, \& Caccoulis, 2012), as it influences what individuals choose to accomplish as members of a team (Bandura, 1997; Short, Sullivan, \& Feltz, 2005), how much they invest in motivational terms for performing actions, how much they work collectively, and how long they persist despite failure (Bandura, 1997). It is understood, therefore, that team members can share a judgment about their collective competence when they are able to allocate, coordinate, and integrate their resources as a group for a specifically situational demand, producing a successful response (Zaccaro, Blair, Peterson, \& Zazanis, 1995).

Different conceptual frameworks (Bandura, 1997; Carron \& Eys, 2012; Fuster-Parra, García-Mas, Ponseti, \& Leo, 2015) and scientific studies (Bray, 2004; Damato, Grove, Eklund, \& Cresswell, 2008; Garza, Ponzanelli, López, Pérez Llantada, \& Garcia-Mas, 2015; Leo, SánchezMiguel, Sánchez-Oliva, Amado, \& García-Calvo, 2011) have highlighted that collective efficacy is one of the most important variables related to performance and success in sports. In the literature, there is the Collective Efficacy Questionnaire for Sports (CEQS) (Short et al., 2005), which evaluates the athletes' perception about the collective efficacy of their team, and their items were constructed to consider attributes of the psychological order of sports teams, aiming not to specify specific actions of the modalities in the technical aspect (Short et al., 2005). The development of CEQS is consistent with the guidelines of Bandura (2006) for the construction of scales of efficacy.

However, although the great relevance of collective effectiveness is identified in different studies (Bray, 2004; Damato et al., 2008; Garza et al., 2015; Leo et al., 2011), in football, the object of analysis of this systematic review, it is not yet clear how this psychological construct is evaluated. It is important to consider that measures of collective effectiveness aim to meet the characteristics of a specific population, with regard to their functioning, and must be developed for the specific domain of the research area (Bandura, 2006). Thus, it becomes of great relevance to investigate how collective efficacy has been assessed in the sports context, considering the instruments used for assessment, the attributes (physical, technical, tactical, or psychological) contemplated in these measurement instruments, and their psychometric properties (Damato et al., 2008; Garza et al., 2015; Leo et al., 2011; Short et al., 2005). It is worth mentioning that the purpose of these instruments should be the operationalization of constructs or latent traits in behaviors that represent them, thus enabling their empirical observation and scientific analysis (Cronbach, 1996; Pasquali, 2010).

Thus, the present systematic had as specific objectives to investigate how collective efficacy has been assessed in the context of soccer and to analyze which psychometric properties and which indicators and attributes have been considered in the instruments used to analyze this psychological construct.

\section{Method}

This study, classified as a systematic review, used statistics as a tool to identify the psychometric properties of the instruments to be investigated (Pasquali, 2010). Systematic reviews can examine trends in psychological factors related to the performance of athletes and assist in the development of appropriate psychological skills training programs (Krane \& Williams, 2006). This review was designed according to the guidelines of the Preferred Reporting Items for Systematic Reviews and Meta-Analyses (PRISMA) (Page et al., 2021). The electronic databases consulted were defined according to the thematic areas that encompass them, as follows: APA (PsychINFO) in the area of psychology; SPORTDiscus in the area of Physical Education; and Science Direct, VHL (Virtual Health Library), Web of Science, Scopus, PubMed, and Scielo (Scientific Electronic Library Online), in the area of Health Sciences.

\section{Eligibility criteria}

The present study included publications in scientific journals and original studies, which specified the instrument used to assess collective efficacy and conducted exclusively with soccer athletes. Course completion papers, dissertations, theses, books, book chapters, conference abstracts, reviews, instrument validation out of the sports context, and studies that did not involve the assessment of collective efficacy in soccer were excluded.

The electronic search strategies were performed using the descriptors collective efficacy (eficácia coletiva) and soccer (futebol), combined by the Boolean operators AND and OR, with terms enclosed by quotation marks (") for compound words, in English, Spanish, and Portuguese ("collective efficacy" OR "eficácia coletiva" OR "eficiencia colectiva") AND ("soccer" OR "futebol" OR "fútbol"). The searches were started in the first half of 2019 and updated in January 2021, and the initial year of publication was not defined.

\section{Data extraction and quality assessment}

Important characteristics of each study (authors, year of publication, aim, participants, assessment instruments, dimensionality, type of response scale, psychometric properties, indicators, and attributes of collective efficacy) were extracted and recorded in Microsoft Excel. Data are depicted in Tables 1 and 2.

The quality analysis of the selected studies was based on the studies of Pasquali (2009), Carretero-Dios and Pérez (2005), and Primi, Muniz, and Nunes (2009) that establish quality indicators for the construction and 
Table 1 Characterization of the studies included in the systematic review

\begin{tabular}{lllll}
\hline $\begin{array}{l}\text { Study } \\
\text { NR }\end{array}$ & Authors (year) & Aims & Participants/age group/level & Main results \\
\hline 1 & $\begin{array}{l}\text { Damato et al. } \\
\text { (2008) }\end{array}$ & $\begin{array}{l}\text { To analyze the effect of the absence of } \\
\text { an important and unimportant player } \\
\text { due to a hypothetical injury on the } \\
\text { collective efficacy of a team. }\end{array}$ & $\begin{array}{l}194 \text { male soccer players/16 to } \\
33 \text { years/semi-professional }\end{array}$ & $\begin{array}{l}\text { Following the injury scenario, } \\
\text { perseverance collective efficacy } \\
\text { perceptions only, significantly decreased } \\
\text { following the loss of either player. }\end{array}$
\end{tabular}

$2 \quad$ Price and Weiss (2011) collective efficacy of a team.

To examine the relation between leadership behaviors perceived by athletes/team, cohesion, and collective efficacy.

18 years/under- 15 and under18

Canonical correlation analyses revealed that (a) peer leaders were characterized by higher perceived soccer competence, peer acceptance, behavioral conduct, and intrinsic motivation and (b) effective peer leadership was associated with players who reported greater task and social cohesion and collective efficacy.

3 Leo et al. (2001b)

To examine the relationships between the motivational climate created by coaches and peers regarding collective efficacy.

$4 \quad$ Leo, SánchezMiguel, SánchezOliva, Alonso, and García-Calvo (2012)

To examine the evolution of the perception of cohesion, self-efficacy, and collective efficacy among male soccer players over the season and their relation with success expectations.
377 male soccer players/ average age $24.51 \pm 3.73 /$ professional

265 male soccer players/15 to 19 years 15 coaches/29 to 45 years/ under-18
The mastery climate created by peers and coaches had a significant and positive relationship to collective efficacy.

The most noteworthy results show that players whose expectations do not match the team's final performance will experience a negative evolution of their levels of perceived cohesion and efficacy, whereas players whose expectations at the start of the season match the team's final performance in the classification will maintain their degree of perceived cohesion and efficacy

$5 \quad$ Leo, SánchezMiguel, SánchezOliva, Amado, and García-Calvo (2013) González-Ponce, Sanchez-Oliva, Amado, and Pulido (2013)

González-Ponce, Sanchez-Oliva, Amado, and Leo (2013) Jowett (2014)

9 Leo, SánchezMiguel, SánchezOliva, Amado, and García-Calvo (2014)

11 Leo, GonzálezPonce, Sánchez-
To examine the conflict of roles and the conflict between teams as facilitators or debilitators of collective efficacy.

To determine the cohesion and collective efficacy profiles of different male soccer players and measure their differences in terms of success expectations, playing time, and performance.

To analyze the relationships between cohesion, collective efficacy, and performance of female soccer players.

To explore differences in the motivational climate of teammates and coaches, cohesion, and collective efficacy of players of both sexes.

To examine the effects of coach leadership and coach-athlete relationship with team efficacy.

To apply a theoretical model evaluating collective efficacy, motivational climate, group cohesion, and their main consequence in performance.

To examine how perceptions of role ambiguity, role conflict, team conflict,
235 male soccer players/15 to 19 years 15 coaches/29 to 45 years/ under-18

Soccer players with higher cohesion and collective efficacy levels belonged to teams that completed the season at the top-level classification. In contrast, athletes with low cohesion and collective efficacy usually played in unsuccessful teams.

66 female soccer players/15 to The importance of unity in solving tasks 33 years/professional and above all the confidence of the players in the capabilities of the group, as this seems to work in favor of obtaining higher performance by the team.

75 male soccer players e 69 female soccer players/15 to 36 years/professional

Female teams had greater scores in social cohesion than male teams, whereas male teams perceived higher peer performance climate than female teams. Furthermore, either both male and female teams, collective efficacy was related to cohesion and peers and coaches mastery climate.

112 male soccer players and 38 Multiple regression analyses revealed that female soccer players/average age $20.07 \pm 1.5 /$ semiprofessional and professional perceptions of both coach leadership and the coach-athlete relationship predicted variance in team efficacy.

203 male soccer players/18 to To optimize perception of collective 37 years/semi-professional efficacy and so, increase performance, it seems important that coaches promote strategies to enhance task-related motivational climate and group cohesion in players.

225 female soccer players/15 to Group conflicts might have more 36 years/professional relevance than role conflict in decreasing confidence in the team's ability to deal with competition.

320 male soccer players and Multilevel modeling analysis showed that 210 female soccer players/ 15 to perceptions of team conflict and 
Table 1 Characterization of the studies included in the systematic review (Continued)

\begin{tabular}{llll}
\hline $\begin{array}{l}\text { Study } \\
\text { NR }\end{array}$ & Authors (year) & Aims & Participants/age group/level \\
\hline & $\begin{array}{l}\text { Miguel, Ivarsson, } \\
\text { and García-Calvo } \\
\text { (2015) }\end{array}$ & $\begin{array}{l}\text { and cohesion can predict collective } \\
\text { efficacy in sports teams. }\end{array}$ & 39 years/professional \\
12 & $\begin{array}{l}\text { Fuster-Parra et al. } \\
\text { (2015) }\end{array}$ & $\begin{array}{l}\text { To analyze the team performance and } \\
\text { collective efficacy through a Bayesian } \\
\text { network. }\end{array}$ & $\begin{array}{l}377 \text { male soccer players/18 to } \\
39 \text { years/semi-professional }\end{array}$
\end{tabular}

Filho, Tenenbaum, and Yang (2015)

Leo, GonzálezPonce, Amado, González, and Calvo (2016) and Martin (2018)

Leo, García-Calvo, et al. (2019)
To explore the interrelation between cohesion, team mental models (1), collective efficacy (2), and perceived performance potential (PPP).
162 male soccer players and 178 female soccer players/20 to 38 years/professional cohesion, at the interpersonal and interteam levels, can predict changes in collective efficacy.

The Bayesian network is used to make inferences regarding our problem, and therefore, we obtain some conclusions; among them are as follows: maximizing the team's performance causes a decrease in collective efficacy and when team's performance achieves the minimum value it causes an increase in moderate/high values of collective efficacy.

The cohesion was found to be an exogenous variable predicting both team mental models and collective efficacy beliefs. Team mental models and collective efficacy were correlated and predicted PPP, which in turn accounted for $59 \%$ of the variance of objective performance scores as measured by teams' season record.

A relationship was found between the perceived performance of the team and the subsequent confidence of the players' team. results and collective efficacy) and perceived team performance.

Study 1: 134 male soccer players/average age $15.09 \pm$ 0.8/under-17

Study 2: 125 male soccer players/average age 17.3土3.6/ under-21

112 male soccer players/13 to 27 years/amateur and semiprofessional teamwork disposition (individual/ collective).

To examine how perceptions of ambiguity and role conflict can predict group cohesion and influence transactional memory and collective efficacy in teams of female soccer players.

To determine the direction of the relationship between cohesion and collective efficacy and its effect on team performance.
225 female soccer players/15 to 36 years/professional

146 male soccer players/15 to 18 years/under-18
The players showed more sense of individualism than collectivism.

The results suggest that the group leaders in female sports teams will have to make an effort to define the roles of each member of the team to improve the union and group work, because these factors are linked to the capacity of sharing knowledge among group members and the confidence in abilities when facing teamwork.

During pre-season and at the start of the season, team sport coaches should focus on social and task aspects, both individually and at a group level. This would improve the perception of collective team efficacy and lead to better team performance.

271 male soccer players/18 to 26 years/semi-professional athletes' perceptions on the effectiveness of their coaches and the collective efficacy of the team.

To explore the interrelationship between cohesion, transactive memory systems (TMS) and collective efficacy through a conceptual model of cohesion.

Analyze the number of task, social, and external leaders within sports teams and examine the effectiveness of different leadership structures in men's and women's teams.

557 soccer professionals/16 to 37 years/professional

317 male soccer players/ average age $25.25 \pm 4.7$ 214 female soccer players/ average age $22.22 \pm 4.41 /$ professional

A canonical correlation analysis between the variants formed by the Coaching Efficacy Scale subscales and the Collective Efficacy Questionnaire for Sport subscales was statistically significant

Task cohesion had a stronger impact on TMS and collective efficacy than social cohesion.

Male teams showed more benefits when having more task and external leaders, while female teams experienced more benefits when having more task and social leaders on the team. 
Table 1 Characterization of the studies included in the systematic review (Continued)

\begin{tabular}{|c|c|c|c|c|}
\hline $\begin{array}{l}\text { Study } \\
\text { NR }\end{array}$ & Authors (year) & Aims & Participants/age group/level & Main results \\
\hline & $\begin{array}{l}\text { and Mellalieu } \\
\text { (2019) }\end{array}$ & $\begin{array}{l}\text { observational learning versus team-level } \\
\text { observational learning interventions on } \\
\text { self-efficacy and collective efficacy beliefs } \\
\text { in team sport athletes. }\end{array}$ & $\begin{array}{l}\text { age } 21.73 \pm 1.51 \\
11 \text { female soccer players/ } \\
\text { average age } 21.94 \pm 1.76 / \\
\text { amateur, semi-professional and } \\
\text { professional }\end{array}$ & $\begin{array}{l}\text { show that individual-level observational } \\
\text { learning, team-level observational learn- } \\
\text { ing, and multi-level observational learning } \\
\text { interventions can enhance efficacy beliefs } \\
\text { in practical contexts and warrant applica- } \\
\text { tion in groups across domains. }\end{array}$ \\
\hline 22 & $\begin{array}{l}\text { Hong and Jeong } \\
(2020)\end{array}$ & $\begin{array}{l}\text { To examine the connection between } \\
\text { transformational and authentic leadership } \\
\text { of head coaches and team performance, } \\
\text { and the mediating role of collective } \\
\text { efficacy in this relationship in the context } \\
\text { of the Korean Men's K League. }\end{array}$ & $\begin{array}{l}106 \text { male soccer players/19 to } \\
40 \text { years/professional }\end{array}$ & $\begin{array}{l}\text { The transformational and authentic } \\
\text { leadership of head coaches both had a } \\
\text { positive effect on players' collective } \\
\text { efficacy, which has a positive effect on } \\
\text { team performance. }\end{array}$ \\
\hline 23 & $\begin{array}{l}\text { Mertens et al. } \\
(2021)\end{array}$ & $\begin{array}{l}\text { To explore how leadership structures } \\
\text { among athletes within sports teams } \\
\text { evolve over the course of a season. }\end{array}$ & $\begin{array}{l}460 \text { male soccer players/ } \\
\text { average age } 23.5 \pm 4.55 / \text { semi- } \\
\text { professional }\end{array}$ & $\begin{array}{l}\text { Findings suggest that leadership } \\
\text { structures in sports teams can change } \\
\text { considerably over the course of the } \\
\text { competitive season, thereby challenging } \\
\text { the classic view of stable, vertical } \\
\text { leadership structures. }\end{array}$ \\
\hline
\end{tabular}

Study NR, numeric reference of study

validation of psychometric instruments, being content validity, construct validity (exploratory factor analysis, confirmatory factor analysis, and convergent/discriminant validity), criterion validity (concurrent or predictive), and reliability (internal consistency and temporal stability). To control the risk of bias, the selection and evaluation of all studies were conducted by two authors independently, being the differences compared and resolved with the participation of a third author for reaching a consensus (Page et al., 2021).

\section{Results}

The initial search yielded a total of 219 studies. Of these, 16 studies were excluded: dissertations $(n=5)$, books ( $=4)$, book chapters $(\mathrm{n}=5)$, and conference abstracts ( $\mathrm{n}$ $=2$ ), resulting in 196 studies. By reading the titles of the articles, duplicate publications were also excluded $(\mathrm{n}=$ 79), thus retaining 117 studies. Posteriorly, researches that had no relation to the sports context $(n=42)$ were excluded, totaling 75 manuscripts.

After reading the abstracts, 46 articles were excluded because they were review papers $(n=11)$ and instrument validation out of the sports context $(\mathrm{n}=$ 4) and that did not involve the assessment of collective efficacy in soccer $(n=31)$, hence resulting in 29 studies for full-text assessment. In this step, five studies were excluded for not mentioning the instruments that evaluated collective efficacy in soccer players and one study that used an instrument that did not assess collective efficacy. The selection process of the reviewed articles is illustrated in Fig. 1.

Table 1 summarizes the characterization of the 23 articles selected for this systematic review.
The largest number of publications was found on collective efficacy in soccer concentrated in 2015 (26.1\%), while the others were published in 2008 (4.3\%), 2011 (8.7\%), 2012 (4.3\%), 2013 (13\%), 2014 (8.7\%), 2016 (8.7\%), 2018 (4.3\%), 2019 (13\%), 2020 (4.3\%), and 2021 (4.3\%).

Most studies (91.3\%) analyzed the relationship of collective efficacy with other variables, being group cohesion and sports performance the most investigated (65.2\%). The participants had, on average, $260.3 \pm 151.1$ soccer players (minimum age of 13 years old and maximum of 40 years old). Six studies (26.1\%) included athletes of both sexes, four (17.4\%) only female athletes, and 13 studies $(56.5 \%)$ only male athletes.

\section{Main results}

Table 2 reveals the instruments used to measure the collective efficacy in soccer athletes, the dimensionality, type of response scale, psychometric properties, indicators, and the collective efficacy attributes evaluated in these instruments.

The 23 studies used standardized instruments, with Likert-type response scales: the Football Collective Efficacy Questionnaire (FCEQ), Collective Efficacy Questionnaire for Sports (CEQS), Collective Efficacy Inventory (CEI), Cuestionario de Eficácia Colectiva Percibida (CEC) - FÚTBOL, and Collective Efficacy Questionnaire for Soccer (CEQsoccer). CEQS (Short et al., 2005), CEC (Garza et al., 2015), and CEQsoccer (Yoo \& Lim, 2009) are characterized as multidimensional measures, with five (ability, preparation, effort, persistence, and unity), four (counterattack, defense, attack, and finalizing actions/transitions), and four (team strength, sufficient training, leader confidence, and effective 
Table 2 Characterization of the instruments used in the studies included in this systematic review

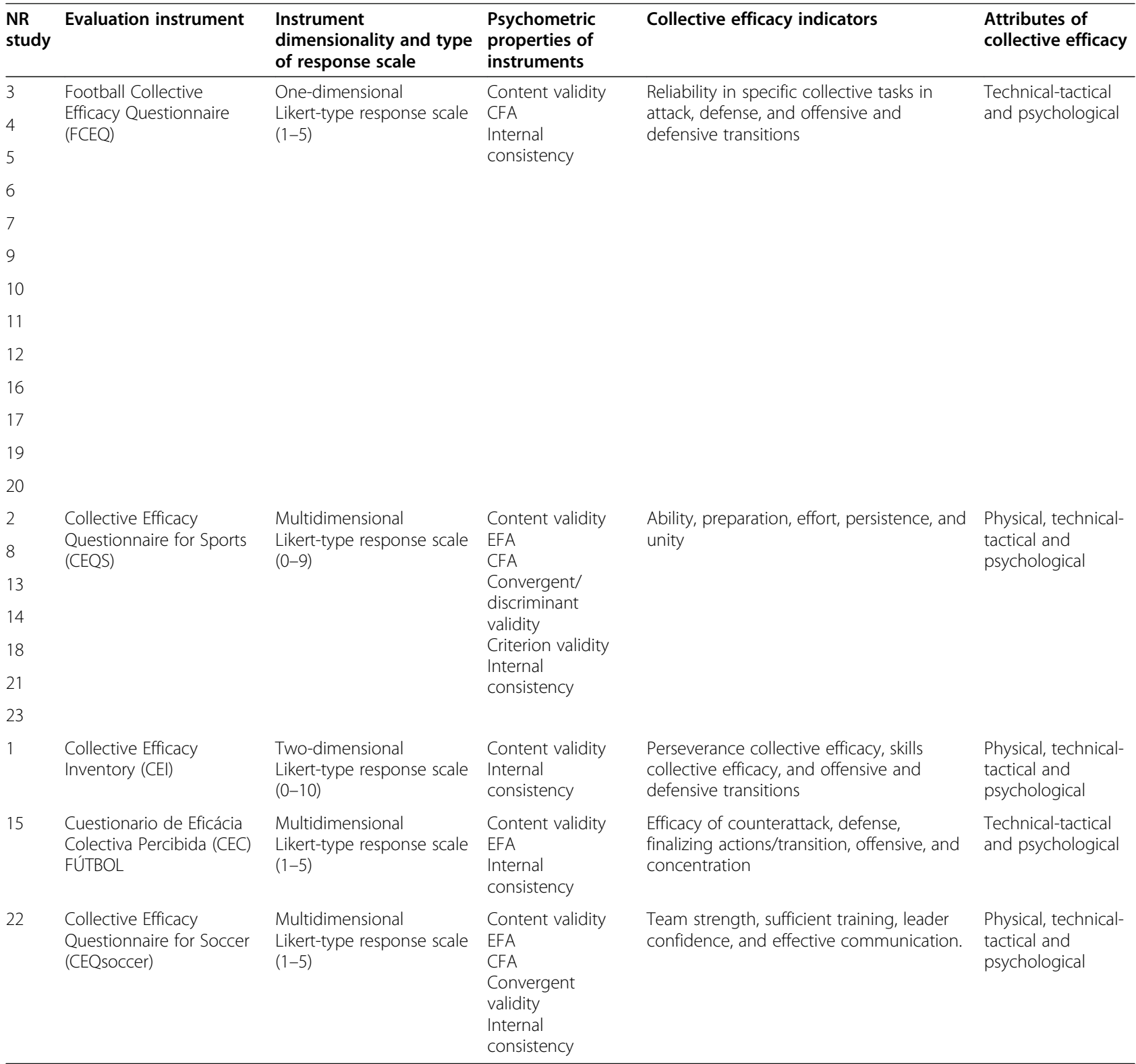

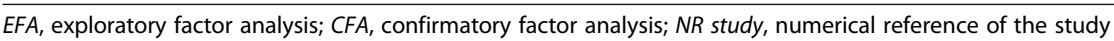

communication) dimensions, respectively. CEI (Damato et al., 2008) is a two-dimensional instrument (perseverance collective efficacy and skills collective efficacy), and FCEQ (Leo et al., 2011) is one-dimensional (collective tasks between attack and defense).

To assess the psychometric properties, the recommended criteria were adopted for the construction and validation of psychometric instruments (Carretero-Dios \& Pérez, 2005; Pasquali, 2009; Primi et al., 2009), establishing as quality indicators the presence of (a) content validity, (b) construct validity (exploratory factor analysis, confirmatory factor analysis, and convergent/discriminant validity), (c) criterion validity (concurrent or predictive), and (d) reliability (internal consistency and temporal stability).

CEQS was the instrument that contemplated a higher number of psychometric properties (six of the seven established as quality criteria): content validity, exploratory factor analysis, confirmatory factor analysis, convergent/discriminant validity, internal consistency, and concurrent validity. Contemplating five psychometric properties is the CEQsoccer (content validity, exploratory factor analysis, confirmatory factor analysis, convergent validity, and internal consistency). FCEQ (content validity, confirmatory factor analysis, and internal consistency) and CEC (content validity, exploratory 


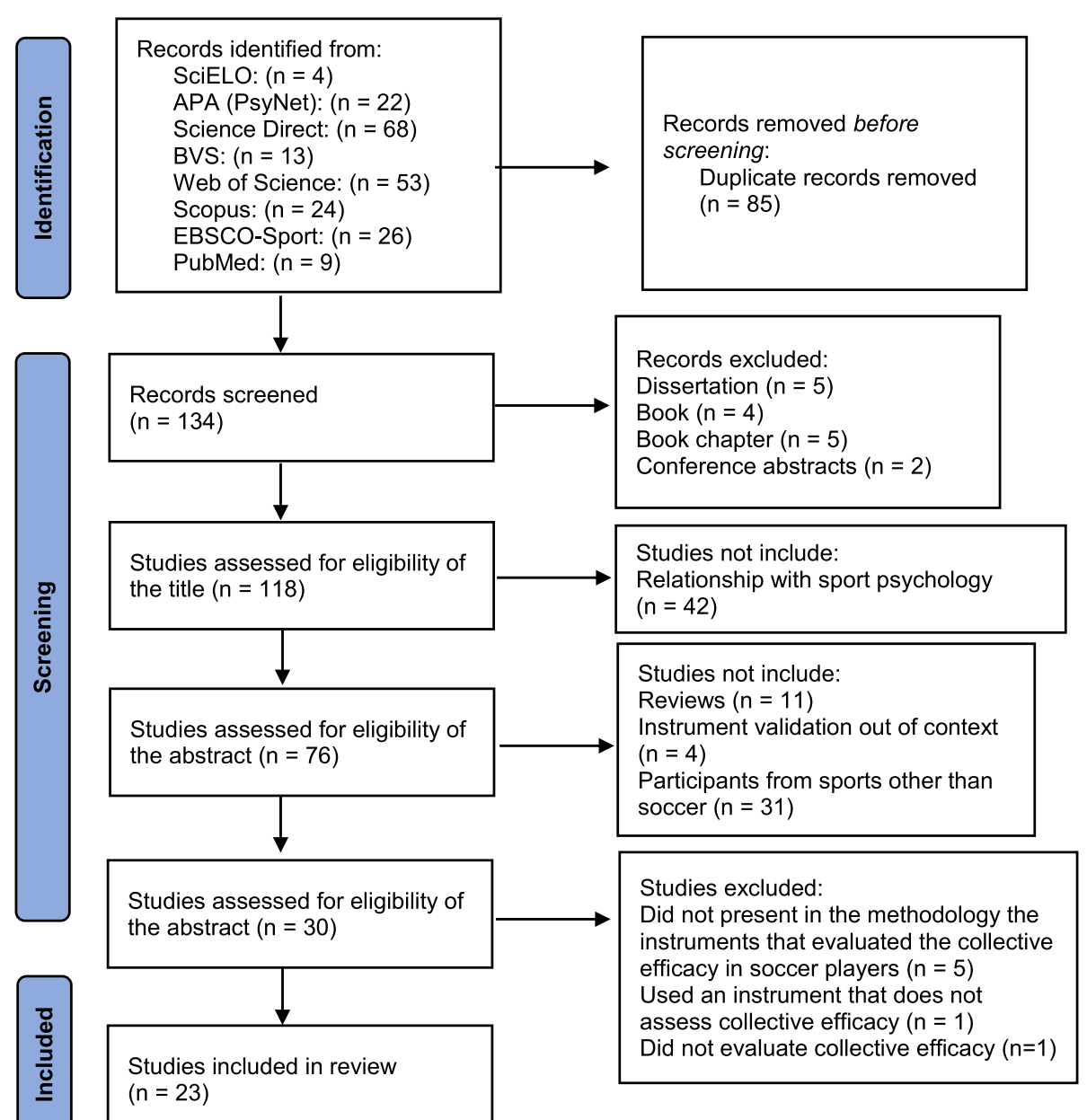

Fig. 1 PRISMA diagram describing the selection process of the reviewed articles

factor analysis, and internal consistency) considered three psychometric properties. In turn, CEI evaluated only two psychometric properties (content validity and internal consistency). Thus, content validity and internal consistency were the most contemplated psychometric properties in the instruments used in the studies that assessed collective efficacy in soccer $(100 \%$ of the research), followed by factor analysis $(95.6 \%$ of the research).

The indicators and attributes of collective efficacy determined in the context of soccer included (a) physical attributes (indicators of strength, speed, and endurance), evaluated in $39.1 \%$ of the studies; (b) technical attributes (indicators related to the fundamentals of the sport), analyzed in $100 \%$ of the studies; (c) tactical attributes (indicators related to specific collective tasks of attack/ defense, counterattack, offensive, and defensive transitions), determined in $100 \%$ of the studies; and (d) psychological attributes (indicators related to confidence, effective communication, concentration, perseverance, preparation, effort, persistence, and union), evaluated in
$100 \%$ of the studies. Specific indicators for assessing collective efficacy in soccer (counterattacks, offensive, and defensive transitions) were found in four instruments (FCEQ, CEQsoccer, CEC, and CEI), covered in 69.6\% of the studies.

\section{Discussion}

The main objective of this work was to investigate how collective efficacy has been assessed in the context of soccer and which psychometric properties, indicators, and attributes were considered in the instruments used.

Instruments elaborated and validated specifically for the soccer context (FCEQ, CEI, CEC, and CEQsoccer) or created to evaluate this construct in different collective sports modalities (CEQS) have been used in the reviewed studies. According to Fransen, Mertens, Feltz, and Boen (2017), the best way to measure a group's beliefs in relation to collective skills is to ask team members about their perceptions of the group's skills rather than their individual skills. 
The importance of using properly validated instruments for the assessment of psychological constructs is defended by several scientific researchers, and they should be developed with the purpose of organizing and explaining aspects of the construct in question and also to obtain reliable results, thereby reducing the chances of errors and bias (Pais-Ribeiro, 2013; Pasquali, 2010; Souza, Alexandre, \& Guirardello, 2017).

In the present systematic review, indicators of content validity, construct validity, and reliability were the most contemplated. The content validity (Pasquali, 2009) was verified through the qualitative analysis of the items among specialists with knowledge about the construct assessed in the five instruments (FCEQ, CEI, CEC, CEQS, and CEQsoccer). The construct validity was measured in CEQS (used in seven studies) and FCEQ (used in 12 studies) instruments, being tested, mainly, through confirmatory factor analysis, considered the most important psychometric analysis in the construction of an assessment instrument, allowing to represent, through statistical calculations, an observational behavior of a latent trait (Pasquali, 2009). The reliability of the instruments used to determine collective efficacy was verified through internal consistency in order to demonstrate the accuracy of the tests, using Cronbach's alpha coefficient to estimate the correlation of each test item and the rest of the items, as well as the correlation between the total score of the items (Pasquali, 2009).

All instruments utilized a Likert-type scale to assess collective efficacy, with a predominance of the 5-point scale (Fuster-Parra et al., 2015; Garza et al., 2015; González-Ponce, Sanchez-Oliva, Amado, \& Leo, 2013; González-Ponce, Sanchez-Oliva, Amado, \& Pulido, 2013; Hong \& Jeong, 2020; Leo et al., 2012; Leo et al., 2013; Leo et al., 2014; Leo, González-Ponce, et al., 2019; Leo, González-Ponce, Amado, et al., 2016; Leo, GonzálezPonce, \& Miguel, 2015; Leo, González-Ponce, SánchezMiguel, et al., 2015; Leo, González-Ponce, SánchezOliva, et al., 2016), which allows the respondent to feel more comfortable in expressing his opinion (Coelho \& Esteves, 2007), for having a neutral response option.

Specific instruments for assessing collective efficacy in soccer players were used in 14 studies (Damato et al., 2008; Fuster-Parra et al., 2015; Garza et al., 2015; González-Ponce, Sanchez-Oliva, Amado, \& Leo, 2013; González-Ponce, Sanchez-Oliva, Amado, \& Pulido, 2013; Hong \& Jeong, 2020; Leo et al., 2012; Leo et al., 2013; Leo et al., 2014; Leo, González-Ponce, et al., 2019; Leo, González-Ponce, Amado, et al., 2016; Leo, González-Ponce, \& Miguel, 2015; Leo, González-Ponce, Sánchez-Miguel, et al., 2015; Leo, González-Ponce, Sánchez-Oliva, et al., 2016). Two studies (Damato et al., 2008; Garza et al., 2015) used instruments developed exclusively to achieve the objective of the study. These instruments aimed to provide a comprehensive evaluation of the construct and different variables of soccer development, namely physical, technical-tactical, and psychological aspects (GonzálezVíllora, Serra-Olivares, Pastor-Vicedo, \& da Costa, 2015).

The studies prioritized the analysis of technical attributes (fundamentals of the modality), tactical (specific collective tasks of attack/defense, counterattack, offensive, and defensive transitions), and psychological (confidence, effective communication, concentration, perseverance, preparation, effort, persistence, and union). The physical aspects were the least contemplated in the instruments used, which may be a limiting factor in the studies recorded herein. According to Bandura (1997), beliefs of collective efficacy must reflect the group's capabilities as substantial implications for its effort and performance in tasks that demand interaction to achieve success, thus requiring a wide range of performances.

\section{Conclusions}

In summary, the results of the present study indicate the use of four instruments developed and validated specifically to assess collective efficacy in the context of soccer, measuring physical, technical, tactical, and psychological attributes. The most mentioned psychometric properties of the studies were restricted to indicators of content validity and reliability (internal consistency). No important analyses were found, such as predictive validity, testretest analysis, and longitudinal analyses in the reviewed studies, which points to incomplete and sometimes inadequate validation processes with regard to the instruments used to measure collective efficacy. The low number of instruments specifically validated for the context of soccer, besides the restriction of the measured psychometric properties (content validity and reliability), may be considered limiting factors for understanding this psychological construct, because it can imply the reliable evaluation of the beliefs of collective efficacy in this modality.

Remarkably, the restriction of searches to the context of soccer, the delimitation of only three languages (English, Spanish, and Portuguese), and the non-inclusion of additional studies beyond the selected works from the databases represent the major limitations of this systematic review. Thus, it is suggested to consider these aspects in future investigations.

Finally, as practical implications, it is worthwhile noting that the present review raises relevant questions regarding the tools used to assess this psychological construct, hence suggesting that future research should focus on expanding the assessment of the psychometric properties of instruments developed specifically for the sport, also contemplating the use of more robust analyses. Such actions may contribute to the reduction of 
biases in the evaluation of the conduct of athletes and assist coaches in the development and improvement of skills related to the group dynamics of sports teams, which are markedly important to achieve the expected success.

\section{Acknowledgements}

We are grateful to CAPES for the financial support provided and to the LAPP ES research group.

\section{Authors' contributions}

MARA and MVSL evaluated the titles and abstracts of each article and selected those with the potential to be included in this review. MJP assisted in writing the results and discussion. MARA and JMFP were the main contributors in writing the manuscript. All authors read and approved the final manuscript.

\section{Funding}

CAPES (Coordenação de Aperfeiçoamento de Pessoal de Nível Superior).

\section{Availability of data and materials}

All data generated or analyzed during this study are included in this published article.

\section{Declarations}

\section{Competing interests}

The authors declare that they have no competing interests.

Received: 29 March 2021 Accepted: 6 June 2021

Published online: 26 June 2021

\section{References}

Atkinson, F., Short, S. E., \& Martin, J. (2018). College soccer players' perceptions of coach and team efficacy. The Sport Psychologist, 32(3), 237-243. https://doi. org/10.1123/tsp.2017-0066.

Bandura, A. (1997). Self-efficacy: The exercise of control. New York: W. H. Freeman.

Bandura, A. (2006). Guide for Constructing Self-Efficacy Scales. In F. Pajares, \& T. Urdan (Eds.), Self-efficacy beliefs of adolescents, (pp. 307-337). Greenwich: Information Age Publishing.

Bandura, A., Azzi, R. G., \& Polydoro, S. (2008). Teoria Social Cognitiva - Conceitos Básicos [Cognitive social theory: basic concepts]. Porto Alegre: Artmed.

Bray, S. R. (2004). Collective efficacy, group goals, and group performance of a muscular endurance task. Small Group Research, 35(1), 230-223. https://doi. org/10.1177/1046496403260531.

Bruton, A. M. Shearer, D. A. \& Mellalieu, S. D. (2019). Who said "there is no 'I' in team"? The effects of observational learning content level on efficacy beliefs in groups. Psychology of Sport and Exercise, 45(2019), 101563. https://doi.org/1 0.1016/.jpsychsport.2019.101563.

Carretero-Dios, H., \& Pérez, C. (2005). Standards for the development and review of instrumental studies. International Journal of Clinical and Health Psychology, 5(3), 521-551.

Carron, A. V., \& Eys, M. A. (2012). Group dynamics in sport. Morgantown: Fitness Information Technology.

Coelho, P. S., \& Esteves, S. P. (2007). The choice between a 5-point and a 10-point scale in the framework of customer satisfaction measurement. International Journal of Market Research, 49(3), 313-339. https://www researchgatenet/ deref/http\%3A\%2F\%2Fdx.doi.org\%2F10.1177\%2F147078530704900503. https://doi.org/10.1177/147078530704900305.

Cronbach, L. (1996). Fundamentos dos testes psicológicos [Fundamentals of psychological testing]. Porto Alegre: Artes Médicas.

Damato, G. C., Grove, R., Eklund, R., \& Cresswell, S. (2008). An exploratory examination into the effect of absence due to hypothetical injury on collective efficacy. The Sport Psychologist, 22(3), 253-268. https:/ /www.resea rchgate.net/deref/http\%3A\%2F\%2Fdx.doi.org\%2F10.1123\%2Ftsp.22.3.253. https://doi.org/10.1123/tsp.22.3.253.

Dominski, F. H., Vilarino, G. T., Coimbra, D. R., Silva, R. B., Casagrande, P. O., \& Andrade, A. (2018). Analysis of scientific production related to sports psychology in sports science journals of Portuguese language. Journal of
Physical Education, 29(e2930), 1-14. https://doi.org/10.4025/jphyseduc.v2 $9 \mathrm{i} 1.2930$

Feltz, D. L., Short, S. E., \& Sullivan, P. J. (2008). Self-efficacy in sport: Reserch and strategies for working with athletes, teams, and coaches. International Journal of Sports Science and Coaching, 3(2), 293-295. https://doi.org/10.1260/174 795408785100699

Filho, E., Tenenbaum, G., \& Yang, Y. (2015). Cohesion, team mental models, and collective efficacy: Towards an integrated framework of team dynamics in sport. Journal of Sports Sciences, 33(6), 641-653. https://doi.org/10.1080/0264 0414.2014.957714.

Fiorese, L., Rodacki, A. L. F., Caruzzo, N. M., Moreira, C. R., Contreira, A. R., Lima, A. M., ... Stefanello, J. M. F. (2019). Sport and exercise psychology studies in Brazil: Performance or health? Frontiers in Psychology, 10, 2154. https://doi. org/10.3389/fpsyg.2019.02154

Fransen, K., Decroos, S., Vanberselares, N., Broek, G. V., De Cuyper, B., Vanroy, J. \& Boen, F. (2015). Is team confidence the key to success? The reciprocal relation between collective efficacy, team outcome confidence, and perceptions of team performance during soccer games. Journal of Sports Sciences. http://dx.doi.org/10.1080/02640414.2014.942689.

Fransen, K., Mertens, N., Feltz, D., \& Boen, F. (2017). "Yes, we can!" review on team confidence in sports. Current Opinion in Psychology, 16, 98-103. https://doi. org/10.1016/j.copsyc.2017.04.024.

Fuster-Parra, P., García-Mas, A., Ponseti, F. J., \& Leo, F. M. (2015). Team performance and collective efficacy in the dynamic psychology of competitive team: a bayesian network analysis. Human Movement Science, 40(1), 98-118. https://doi.org/10.1016/j.humov.2014.12.005.

Garza, R. C. A., Ponzanelli, R., López, L. A., Pérez Llantada, M. C., \& Garcia-Mas, A. (2015). Individualism and collectivism in relation to perceived collective efficacy in soccer players. Revista Mexicana de Psicología, 32(1), 68-80.

González-Ponce, I., Sanchez-Oliva, D., Amado, D., \& Leo, F. M. (2013). Analysis of the group processes regarding sex in the semiprofessional sport contexto. Cuadernos de Psicología del Deporte, 13(2), 45-52. https://doi.org/10.4321/S1 578-84232013000200005.

González-Ponce, I, Sanchez-Oliva, D, Amado, D \& Pulido, J. J. (2013). Analysis of cohesion, collective efficacy and performance in women's soccer teams. Apunts Educación Física y Deportes, 114(4), 65-71. https://doi.org/10.5672/a punts.2014-0983.es.(2013/4).114.07.

González-Víllora, S., Serra-Olivares, J., Pastor-Vicedo, J. C., \& da Costa, I. T. (2015). Review of the tactical evaluation tools for youth players, assessing the tactics in team sports: Football. Springer Plus, 4(663), 1-17. https://doi.org/10.1186/s4 0064-015-1462-0.

Hampson, R., \& Jowett, S. (2014). Effects of coach leadership and coach-athlete relationship on collective efficacy. Scandinavian Journal of Medicine and Science in Sports, 24(2), 454-460. https://doi.org/10.1111/j.1600-0838.2012.01527.x.

Hong, E., \& Jeong, Y. (2020). Coach leadership style and Korean professional soccer team performance: Collective efficacy as a mediator. Social Behavior and Personality: An International Journal, 48(8), e9307. https://doi.org/10.2224/ sbp.9307.

Jowett, S., Shanmugam, V., \& Caccoulis, S. (2012). Collective efficacy as a mediator of the association between inter personal relationships and athlete satisfaction in team sports. International Journal of Sport and Exercise Psychology, 10(1), 66-78. https://doi.org/10.1080/1612197X.2012.645127.

Krane, V., \& Williams, J. M. (2006). Psychological characteristics of peak performance. In J. M. Williams (Ed.), Applied sport psychology personal growth to peak performance, (pp. 207-220). McGraw-Hill Companies.

Leo, F. M., García-Calvo, T., González-Ponce, I., Pulido, J. J., \& Fransen, K. (2019). How many leaders does it take to lead a sports team? The relationship between the number of leaders and the effectiveness of professional sports teams. PLoS One, 14(6), e0218167. https://doi.org/10.13 71/journal.pone.0218167.

Leo, F. M., González-Ponce, I., Amado, A. D., González, J. J. P., \& Calvo, T. G. (2016). An approachment to group processes in female professional sport. European Journal of Human Movement, 36, 57-74.

Leo, F. M., González-Ponce, I., García-Calvo, T., Sánchez-Oliva, D., \& Filho, E. (2019). The relationship among cohesion, transactive memory systems, and collective efficacy in professional soccer teams: a multilevel structural equation analysis. Group Dynamics: Theory, Research, and Practice, 23(1), 4456. https://doi.org/10.1037/gdn0000097.

Leo, F. M., González-Ponce, I., \& Miguel, P. A. S. (2015). Role conflict and team conflict as undermining collective efficacy. Revista de Psicología del Deporte, $24,171-176$. 
Leo, F. M., González-Ponce, I., Sánchez-Miguel, P. A., Ivarsson, A., \& García-Calvo, T. (2015). Role ambiguity, role conflict, team conflict, cohesion, and collective efficacy in sport teams: A multilevel analysis. Psychology of Sport and Exercise, 20, 60-66. https://doi.org/10.1016/j.psychsport.2015.04.009.

Leo, F. M., González-Ponce, I., Sánchez-Oliva, D., Amado, D., \& García-Calvo, T. (2016). Exploring direction between cohesion and collective efficacy and relationships with performance of football teams. South African Journal for Research in Sport, Physical Education and Recreation, 38(3), 113-126.

Leo, F. M., Sánchez-Miguel, P. A., Sánchez-Oliva, D., Alonso, D. A., \& García-Calvo, T. (2012). Evolution of perceived cohesion and efficacy over the season and their relation to success expectations in soccer teams. Journal of Human Kinetics, 34, 129-138. https://doi.org/10.2478/2Fv10078-012-0072-y.

Leo, F. M., Sánchez-Miguel, P. A., Sánchez-Oliva, D., Amado, D., \& García-Calvo, T. (2011). Incidence of the cooperation, cohesion and collective efficacy on performance in football teams. Revista Internacional de Ciencias del Deporte, 26(7), 341-354. https://doi.org/10.5232/ricyde2011.02601.

Leo, F. M., Sánchez-Miguel, P. A., Sánchez-Oliva, D., Amado, D., \& García-Calvo, T. (2011b). Analysis of motivational climate as the background to collective efficacy in semi-professional football players. Revista de Psicología del Deporte, 21(1), 159-162.

Leo, F. M., Sánchez-Miguel, P. A., Sánchez-Oliva, D., Amado, D., \& García-Calvo, T. (2013). Analysis of cohesion and collective efficacy profiles for the performance of soccer players. Journal of Human Kinetics, 39(1), 221-229. https://doi.org/10.2478/hukin-2013-0085.

Leo, F. M., Sánchez-Miguel, P. A., Sánchez-Oliva, D., Amado, D., \& García-Calvo, T. (2014). Analysis of the group process and the performance in semiprofessional soccer. Revista Internacional de Medicina y Ciencias de la Actividad Física y el Deporte, 14(53), 153-168.

Mertens, N., et al. (2021). Will the real leaders please stand up? The emergence of shared leadership in semi-professional soccer teams. Journal of Science and Medicine in Sport, 24(2021), 281-290. https://doi.org/10.1016/j.jsams.2020.09.007.

Page, M. J., McKenzie, J. E., Bossuyt, P. M., Boutron, I., Hoffmann, T. C., Mulrow, C. D., ... Moher, D. (2021). The PRISMA 2020 statement: an updated guideline for reporting systematic reviews. BMJ, 372, 71. https://doi.org/10.1136/bmj.n71.

Pais-Ribeiro, J. L. (2013). Measurement in psychological assessment. Psicologia, Saúde e Doenças, 14, 245-263. https://doi.org/10.15309/13psd140116.

Pasquali, L. (2009). Psychometric. Revista da Escola de Enfermagem da USP, 43(spe), 992-999. https://doi.org/10.1590/S0080-62342009000500002.

Pasquali, L. (2010). Instrumentação psicológica- Fundamentos e práticas [Psychological instrumentation: fundamentals and practices]. Porto Alegre: Artmed.

Price, M. S., \& Weiss, M. R. (2011). Peer leadership in sport: Relationships among personal characteristics, leader behaviors, and team outcomes. Journal of Applied Sport Psychology, 23(1), 49-64. https:/doi.org/10.1080/10413200.2010.520300.

Primi, R., Muniz, M., \& Nunes, C. H. S. S. (2009). Definições contemporâneas de validade dos testes psicológicos [Contemporary definitions of validity of psychological tests]. In C. S. Hutz (Ed.), Avanços e controvérsias na avaliação psicológica [Advances and controversies in psychological assessment], (pp. 243265). São Paulo: Casa do Psicólogo.

Short, S. E., Sullivan, P., \& Feltz, D. L. (2005). Development and preliminary validation of the collective efficacy questionnaire for sports. Measurement in Physical Education and Exercise Science, 9(3), 181-202. https://doi.org/10.1207/ s15327841mpee0903_3.

Souza, A. C., Alexandre, N. M. C., \& Guirardello, E. B. (2017). Psychometric properties in instruments evaluation of reliability and validity. Epidemiologia e Serviços de Saúde, 26(3), 649-659. https://doi.org/10.5123/s1679-4974201 7000300022

Trevelin, F., \& Alves, C. F. (2019). Sports psychology: Literature review about relationships between emotions and athlete performance. Psicologia Revista, 27, 545-562. https://doi.org/10.23925/2594-3871.2018v27i3p545-562.

Vilarino, G. T., Andrade, F. H., Felden, R. D., Fomes, E. P., \& Andrade, A. (2017). Analysis of research groups of psychology of sport and exercise in Brazil. Revista Brasileira de Ciências do Esporte, 39(4), 371-379. https://doi.org/10.101 6/j.rbce.2017.07.004

Yeemin, W., Dias, C. S., \& Fonseca, A. M. (2016). A Systematic review of psychological studies applied to futsal. Journal of Human Kinetics, 50(1), 247257. https://www.ncbi.nlm.nih.gov/pmc/articles/PMC5260660/. https://doi. org/10.1515/hukin-2015-0162.

Yoo, J., \& Lim, S. (2009). Development and validation of the Collective Efficacy Questionnaire for Soccer [In Korean]. Korean Journal of Sport Psychology, 20, 17-31 Retrieved from https://bit.ly/36lf2au.
Zaccaro, S. J., Blair, V., Peterson, C., \& Zazanis, M. (1995). Collective efficacy. In J. E. Maddux (Ed.), The Plenum series in social/clinical psychology. Self-efficacy, adaptation, and adjustment: Theory, research, and application, (pp. 305-328). Plenum Press. https://doi.org/10.1007/978-1-4419-6868-5_11.

\section{Publisher's Note}

Springer Nature remains neutral with regard to jurisdictional claims in published maps and institutional affiliations.

\section{Submit your manuscript to a SpringerOpen ${ }^{\circ}$ journal and benefit from:}

- Convenient online submission

- Rigorous peer review

- Open access: articles freely available online

- High visibility within the field

- Retaining the copyright to your article

Submit your next manuscript at $\boldsymbol{\nabla}$ springeropen.com 